\title{
Prevention of postoperative nausea and vomiting by metoclopramide combined with dexamethasone: randomised double blind multicentre trial
}

\author{
Jan Wallenborn, Götz Gelbrich, Detlef Bulst, Katrin Behrends, Hasso Wallenborn, Andrea Rohrbach, Uwe Krause, \\ Thomas Kühnast, Martin Wiegel, Derk Olthoff
}

\begin{abstract}
Objectives To determine whether $10 \mathrm{mg}, 25 \mathrm{mg}$, or $50 \mathrm{mg}$ metoclopramide combined with $8 \mathrm{mg}$ dexamethasone, given intraoperatively, is more effective in preventing postoperative nausea and vomiting than $8 \mathrm{mg}$ dexamethasone alone, and to assess benefit in relation to adverse drug reactions.

Design Four-armed, parallel group, double blind, randomised controlled clinical trial.

Setting Four clinics of a university hospital and four district hospitals in Germany.

Participants 3140 patients who received balanced or regional anaesthesia during surgery.

Main outcome measures Postoperative nausea and vomiting within 24 hours of surgery (primary end point); occurrence of adverse reactions.

Results Cumulative incidences (95\% confidence intervals) of postoperative nausea and vomiting were $23.1 \%$ (20.2\% to $26.0 \%$ ), $20.6 \%$ (17.8\% to $23.4 \%), 17.2 \%$ (14.6\% to $19.8 \%$ ), and $14.5 \%$ (12.0\% to $17.0 \%)$ for $0 \mathrm{mg}, 10 \mathrm{mg}, 25 \mathrm{mg}$, and $50 \mathrm{mg}$ metoclopramide. In the secondary analysis, $25 \mathrm{mg}$ and $50 \mathrm{mg}$ metoclopramide were equally effective at preventing early nausea (0-12 hours), but only $50 \mathrm{mg}$ reduced late nausea and vomiting ( $>12$ hours). The most frequent adverse drug reactions were hypotension and tachycardia, with cumulative incidences of $8.8 \%$ (6.8\% to $10.8 \%), 11.2 \%$ (9.0\% to $13.4 \%$ ), $12.9 \%$ (10.5\% to $15.3 \%$ ), and $17.9 \%$ (15.2\% to $20.6 \%$ ) for $0 \mathrm{mg}$, $10 \mathrm{mg}, 25 \mathrm{mg}$, and $50 \mathrm{mg}$ metoclopramide.

Conclusion The addition of $50 \mathrm{mg}$ metoclopramide to $8 \mathrm{mg}$ dexamethasone (given intraoperatively) is an effective, safe, and cheap way to prevent postoperative nausea and vomiting. A reduced dose of $25 \mathrm{mg}$ metoclopramide intraoperatively, with additional postoperative prophylaxis in high risk patients, may be equally effective and cause fewer adverse drug reactions.

Trial registration Current Controlled Trials ISRCTN31625370.
\end{abstract}

\section{Introduction}

Despite improvements in anaesthesia, $20-30 \%$ of patients still experience nausea and vomiting after surgery. ${ }^{1-4} \mathrm{~A}$ large clinical trial of postoperative nausea and vomiting showed that $4 \mathrm{mg}$ ondansetron, $4 \mathrm{mg}$ dexamethasone, or $1.25 \mathrm{mg}$ droperidol were effective (odds ratios about 0.5 ), and that combinations of these drugs had an additive effect. ${ }^{1}$ Dexamethasone was recommended as the first line drug, as it is safe and cheap.
Data on metoclopramide as an antiemetic after surgery are contradictory. A meta-analysis found that an intravenous dose of $10 \mathrm{mg}$ had only a marginal effect, ${ }^{5}$ but because of its complex mode of action (it binds to dopamine, serotonin, and histamine receptors), metoclopramide remains an interesting drug for preventing postoperative nausea and vomiting. ${ }^{6}$ Studies have concluded that metoclopramide is ineffective in this context, but the timing of administration and use of larger doses were not investigated fully. ${ }^{7-10}$ We investigated the efficacy and safety of three doses of metoclopramide $(10 \mathrm{mg}, 25 \mathrm{mg}$, and $50 \mathrm{mg}$ ), on the assumption that each patient would receive basic antiemetic prophylaxis of $8 \mathrm{mg}$ dexamethasone.

\section{Methods}

\section{Protocol}

We considered patients for inclusion if they were aged 18 years or more and having regional or balanced anaesthesia during hysterectomy, cholecystectomy, herniotomy, otolaryngological surgery, thyroidectomy, total knee or hip replacement, or arthroscopy of the shoulder or the knee. Exclusion criteria were contraindications for metoclopramide; use of antiemetic or antidepressive drugs; patient classified as American Society of Anesthesiologists grade IV (has severe systemic disease that is a constant threat to life); presence of extrapyramidal motoric disease, malignant hyperthermia, hepatic insufficiency, pheochromocytoma, mechanical ileus or epilepsy; intended or probable postoperative administration of propofol, artificial respiration, or stomach tube; patient pregnant or breast feeding; and current participation in another clinical trial. All patients gave informed consent in writing the day before surgery.

We randomised patients to receive $0 \mathrm{mg}, 10 \mathrm{mg}, 25 \mathrm{mg}$, or 50 mg metoclopramide (MCP-ratiopharm, ratiopharm $\mathrm{GmbH}$ ) and the standard $8 \mathrm{mg}$ dexamethasone (Fortecortin, Merck). Both drugs were given intravenously 30-60 minutes before the anticipated end of surgery or immediately after the start of anaesthesia if surgery was expected to take less than one hour. If postoperative nausea and vomiting occurred, $62 \mathrm{mg}$ dimenhydrinate or $12.5 \mathrm{mg}$ dolasetron was given as the rescue drug.

\section{Assignment and masking}

We generated blocked randomisation lists stratified by centre, sex, and type of surgery. Study nurses randomised patients immediately before the trial drug was administered. The anaesthesiologists (who recorded the end points) and the patients were blinded to the assignment. 


\section{Documentation and follow-up}

We recorded eligibility criteria and history on the day before surgery. During surgery, details of anaesthesia, relevant drug, and adverse reactions were recorded. Twenty four hours after the end of surgery the anaesthesiologists visited the patients to record any nausea and vomiting, other adverse events, and relevant drugs.

\section{Statistical analysis}

The primary end point was occurrence of nausea and vomiting within 24 hours of the end of surgery. Secondary end points were nausea and vomiting separately, occurrence of early $(\leq 12$ hours) and late $(>12$ hours after surgery, including repeat events) postoperative nausea and vomiting, occurrence of multiple episodes of nausea and vomiting, and need for rescue drug. We used the $\chi^{2}$ test to compare the frequency of nausea and vomiting in the four treatment groups. Safety end points were the occurrence of adverse reactions after the study drug was given and postoperative adverse events. We performed a trend test using Kendall's $\tau$ (for event rate increasing with dose) and Fisher's exact test (for increased event rate in the presence of any dose of metoclopramide) for each end point. One sided $\mathrm{P}$ values are given for both tests; $95 \%$ confidence intervals are given for estimates of the main efficacy and safety outcomes. We performed stepwise multiple logistic regression analyses of early and late postoperative nausea and vomiting and adverse drug reactions to identify predictors of these events. The results are presented as adjusted odds ratios with 95\% confidence intervals; we adjusted for all variables that were independently explanatory $(\mathrm{P} \leq 0.05)$ for the respective end point. Analyses were performed according to the intent to treat principle. We used SPSS 11.0 and StatXact 5 statistical software.

\section{Sample size}

We set the total sample size at 3000 to achieve a power of 0.98 for detecting the difference between putative postoperative nausea and vomiting rates of $30 \%, 25 \%, 22.5 \%$, and $20 \%$ for $0 \mathrm{mg}, 10$ $\mathrm{mg}, 25 \mathrm{mg}$, and $50 \mathrm{mg}$ metoclopramide, respectively, by using the $\chi^{2}$ test at a significance level of 0.05 .

\section{Results}

\section{Study sample}

We screened 4078 patients from January to November 2004; we included 3149 in the study and analysed 3140 (fig 1). Three patients in the $50 \mathrm{mg}$ group did not receive metoclopramide because of dilatative cardiomyopathy, arrhythmia, and intraoperative vomiting. These patients were included in the intent to treat analysis. Table 1 summarises demographic data and putative risk factors.

\section{End points}

The addition of $10 \mathrm{mg}, 25 \mathrm{mg}$, and $50 \mathrm{mg}$ metoclopramide reduced the cumulative incidence of postoperative nausea and vomiting from $23.1 \%$ (95\% confidence interval $20.2 \%$ to $26.0 \%$ ) to $20.6 \%$ ( $17.8 \%$ to $23.4 \%$ ), $17.2 \%$ (14.6\% to $19.8 \%$ ), and $14.5 \%$ $(12.0 \%$ to $17.0 \%)$, respectively. The corresponding numbers needed to treat are 40.0 (not significant), 16.9 (10.1 to 52.6), and 11.6 (8.0 to 20.8). Whereas overall rates (irrespective of the time of postoperative nausea and vomiting) suggest "the more, the better," $25 \mathrm{mg}$ metoclopramide was as effective in preventing early events as $50 \mathrm{mg}$, but only the $50 \mathrm{mg}$ dose reduced nausea and vomiting in the late phase. Metoclopramide also reduced the number of multiple episodes of nausea and vomiting and the need for rescue drugs (table 2).

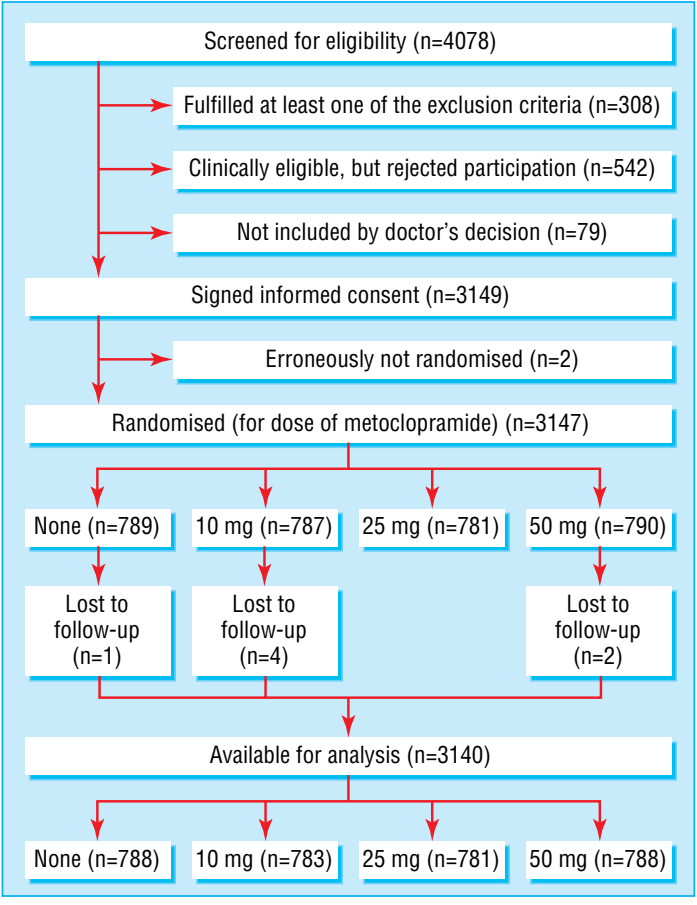

Fig 1 Flow of participants through trial

The incidence of postoperative nausea and vomiting decreased continuously up to 12 hours after surgery, but increased after that point (fig 2). Moreover, the curves for the 25

Table 1 Demographic data and potential risk factors for postoperative nausea and vomiting. Values are number $(\%)$

\begin{tabular}{|c|c|c|c|c|}
\hline \multirow{2}{*}{ Variable } & \multicolumn{4}{|c|}{ Dose of metoclopramide $(\mathrm{mg})$} \\
\hline & $0(n=788)$ & $10(n=783)$ & $25(n=781)$ & $50(n=788)$ \\
\hline Female sex & $452(57.4)$ & $450(57.5)$ & $442(56.6)$ & $447(56.7)$ \\
\hline Age $>50$ years & $471(59.8)$ & $489(62.5)$ & $473(60.6)$ & $494(62.7)$ \\
\hline Obesity (body mass index $>30$ ) & $240(30.5)$ & $233(29.8)$ & $225(28.8)$ & $243(30.8)$ \\
\hline Diabetes mellitus & $97(12.3)$ & $98(12.5)$ & $106(13.6)$ & $100(12.7)$ \\
\hline Renal insufficiency & $12(1.5)$ & $5(0.6)$ & $4(0.5)$ & $8(1.0)$ \\
\hline $\begin{array}{l}\text { Chronic obstructive pulmonary } \\
\text { disease }\end{array}$ & $42(5.3)$ & $53(6.8)$ & $60(7.7)$ & $64(8.1)$ \\
\hline $\begin{array}{l}\text { History of postoperative nausea } \\
\text { and vomiting or motion sickness }\end{array}$ & $208(26.4)$ & $216(27.6)$ & $204(26.1)$ & $220(27.9)$ \\
\hline Non-smoker & $600(76.1)$ & $606(77.4)$ & $617(79.0)$ & $634(80.5)$ \\
\hline \multicolumn{5}{|l|}{ Type of surgery } \\
\hline \multicolumn{5}{|l|}{ Surgery with intubation: } \\
\hline Hysterectomy & $58(7.4)$ & $56(7.2)$ & $58(7.4)$ & $58(7.4)$ \\
\hline Cholecystectomy & $57(7.2)$ & $56(7.2)$ & $57(7.3)$ & $55(7.0)$ \\
\hline Herniotomy & $64(8.1)$ & $59(7.5)$ & $61(7.8)$ & $62(7.9)$ \\
\hline Otolaryngological surgery & $116(14.7)$ & $114(14.6)$ & $117(15.0)$ & $118(15.0)$ \\
\hline Thyroidectomy & $68(8.6)$ & $75(9.6)$ & $71(9.1)$ & $71(9.0)$ \\
\hline Endoprothesis & $60(7.6)$ & $66(8.4)$ & $58(7.4)$ & $54(6.9)$ \\
\hline Arthroscopy & $148(18.8)$ & $148(18.9)$ & $156(20.0)$ & $147(18.7)$ \\
\hline \multicolumn{5}{|l|}{ Surgery with regional anaesthesia: } \\
\hline Endoprothesis & $156(19.8)$ & $149(19.0)$ & $154(19.7)$ & $158(20.1)$ \\
\hline Arthroscopy & $61(7.7)$ & $60(7.7)$ & $49(6.3)$ & $65(8.2)$ \\
\hline \multicolumn{5}{|l|}{ Alcohol consumption* } \\
\hline None & $410(52.0)$ & $396(50.6)$ & $398(51.0)$ & $378(48.0)$ \\
\hline 1-14 drinks each week & $320(40.6)$ & $331(42.3)$ & $331(42.4)$ & $348(44.2)$ \\
\hline$>14$ drinks each week & $58(7.4)$ & $56(7.2)$ & $52(6.7)$ & $62(7.9)$ \\
\hline \multicolumn{5}{|l|}{ Opioids } \\
\hline Intraoperatively & $576(73.1)$ & $580(74.1)$ & $566(72.5)$ & $563(71.5)$ \\
\hline$\leq 12$ hours postoperatively & $419(53.2)$ & $416(53.1)$ & $404(51.7)$ & $393(49.9)$ \\
\hline$>12$ hours postoperatively & $223(28.3)$ & $202(25.8)$ & $205(26.2)$ & $192(24.4)$ \\
\hline
\end{tabular}

${ }^{*}$ One drink=0.25 litre beer, 0.1 litre wine, or $20 \mathrm{ml}$ spirits. 
Table 2 Dose of metoclopramide and postoperative nausea and vomiting outcomes. Values are number (\%) unless stated otherwise

\begin{tabular}{|c|c|c|c|c|c|}
\hline \multirow{2}{*}{ Variable } & \multicolumn{4}{|c|}{ Dose of metoclopramide $(\mathrm{mg})$} & \multirow{2}{*}{$P$ value } \\
\hline & $0(n=788)$ & $10(n=783)$ & $25(n=781)$ & $50(n=788)$ & \\
\hline All types of postoperative nausea and vomiting & $182(23.1)$ & $161(20.6)$ & $134(17.2)$ & $114(14.5)$ & $<0.001$ \\
\hline Nausea (regardless of vomiting) & $147(18.7)$ & $129(16.5)$ & $110(14.1)$ & $84(10.7)$ & $<0.001$ \\
\hline Vomiting (regardless of nausea) & $134(17.0)$ & $106(13.5)$ & $94(12.0)$ & $80(10.2)$ & 0.001 \\
\hline Early form (0-12 hours after surgery) & $138(17.5)$ & $116(14.8)$ & $84(10.8)$ & $85(10.8)$ & $<0.001$ \\
\hline Late form (>12-24 hours after surgery), including repeat episodes & $67(8.5)$ & $57(7.3)$ & $62(7.9)$ & $38(4.8)$ & 0.025 \\
\hline Multiple episodes of nausea and vomiting & 77 (9.8) & $54 \quad(6.9)$ & $46 \quad(5.9)$ & $46(5.8)$ & 0.007 \\
\hline Need for rescue drugs after nausea and vomiting & $99(12.6)$ & $79(10.1)$ & $67(8.6)$ & $57(7.2)$ & 0.003 \\
\hline
\end{tabular}

$\mathrm{mg}$ and $50 \mathrm{mg}$ groups diverged in the later phase. These findings justify setting the cut-off point at 12 hours to distinguish between early and late events.

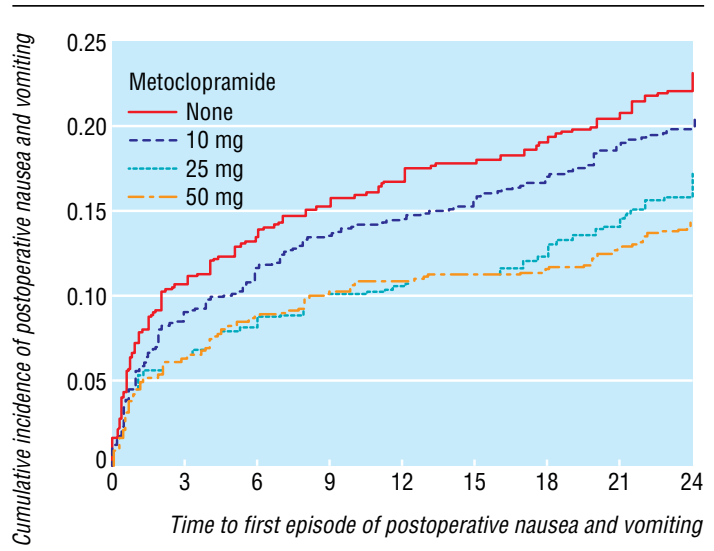

\section{Adverse events}

Only intraoperative hypotension and tachycardia were clearly related to metoclopramide (table 3), and these events correlated with each other $(\mathrm{P}<0.001)$. The incidence of either of these events was $8.8 \%$ (6.8\% to $10.8 \%$ ), $11.2 \%$ (9.0\% to $13.4 \%), 12.9 \%$ ( $10.5 \%$ to $15.3 \%$ ), and $17.9 \%$ (15.2\% to $20.6 \%$ ) for $0 \mathrm{mg}, 10 \mathrm{mg}$, $25 \mathrm{mg}$, and $50 \mathrm{mg}$ metoclopramide; this corresponded to numbers needed to harm of 41.7 (not significant), 24.4 (13.9 to 100.0), and 11.0 (8.1 to 17.2). Metoclopramide was also associated with dyskinesia or extrapyramidal symptoms (number needed to harm: 156, 81 to 3333 for doses of $25 \mathrm{or} 50 \mathrm{mg}$ ), impaired taste and smell (167, 93 to 5000 for any dose), and hot flushes (182, 106 to 345 for any dose), but the results were only marginally significant (table 3 ).

Serious adverse events were bleeding (four), myocardial infarction (one), tachycardia and hypotension (one), aspiration (one), and inspiratoric stridor with cyanosis (one); these events were classified as definitely (five) or probably (three) not related to metoclopramide.

Fig 2 Cumulative incidence of postoperative nausea and vomiting in four treatment groups

Table 3 Relation between dose of metoclopramide and adverse events. Values are number (\%) unless stated otherwise

\begin{tabular}{|c|c|c|c|c|c|c|}
\hline \multirow{2}{*}{ Variable } & \multicolumn{4}{|c|}{ Dose of metoclopramide (mg) } & \multirow{2}{*}{ Trend (P value)* } & \multirow{2}{*}{$\begin{array}{l}\text { Fisher's exact test } \\
(\mathrm{P} \text { value }) \dagger\end{array}$} \\
\hline & $0(n=788)$ & $10(n=783)$ & $25 \quad(n=781)$ & $50(n=788)$ & & \\
\hline \multicolumn{7}{|l|}{ Events after metoclopramide was given } \\
\hline Hypotension & $62(7.9)$ & $74(9.5)$ & $88(11.3)$ & $113(14.3)$ & $<0.001$ & 0.001 \\
\hline Hypertension & $17(2.2)$ & $18(2.3)$ & $15(1.9)$ & $22(2.8)$ & 0.267 & 0.446 \\
\hline Tachycardia & $7(0.9)$ & $16(2.0)$ & $19(2.4)$ & $38(4.8)$ & $<0.001$ & $<0.001$ \\
\hline Bradycardia & $10(1.3)$ & $8(1.0)$ & $7(0.9)$ & $5(0.6)$ & 0.895 & 0.801 \\
\hline Arrhythmia with unchanged heart rateł & $2(0.3)$ & $0(0.0)$ & $2(0.3)$ & $2(0.3)$ & 0.393 & 0.532 \\
\hline Skin reaction‡ & $2(0.3)$ & $1(0.1)$ & $1(0.1)$ & $5(0.6)$ & 0.085 & 0.402 \\
\hline \multicolumn{7}{|l|}{ Postoperative events } \\
\hline Headache & $82(10.4)$ & $78(10.0)$ & $81(10.4)$ & $76(9.7)$ & 0.653 & 0.608 \\
\hline Dizziness & $42(5.3)$ & $35(4.5)$ & $35(4.5)$ & $32(4.1)$ & 0.871 & 0.854 \\
\hline Sedation or fatigue (or both) & $59(7.5)$ & $53(6.8)$ & $76(9.7)$ & $65(8.2)$ & 0.113 & 0.275 \\
\hline Dry mouth & $72(9.1)$ & $91(11.6)$ & $78(10.0)$ & $76(9.6)$ & 0.508 & 0.168 \\
\hline Alteration of taste or smell (or both) & $1(0.1)$ & $6(0.8)$ & $5(0.6)$ & $6(0.8)$ & 0.059 & 0.038 \\
\hline Itching & $6(0.8)$ & $5(0.6)$ & $6(0.8)$ & $7(0.9)$ & 0.361 & 0.397 \\
\hline Skin reaction $\ddagger$ & $3(0.4)$ & $3(0.4)$ & $4(0.5)$ & $0(0.0)$ & 0.854 & 0.523 \\
\hline Allergy $\ddagger$ & $1(0.1)$ & $1(0.1)$ & $1(0.1)$ & $1(0.1)$ & 0.512 & 0.737 \\
\hline Delirium on awakening $\ddagger$ & $2(0.3)$ & $5(0.6)$ & $3(0.4)$ & $2(0.3)$ & 0.555 & 0.387 \\
\hline Central anticholinergic syndromeł & $3(0.4)$ & $1(0.1)$ & $8(1.0)$ & $3(0.4)$ & 0.222 & 0.458 \\
\hline $\begin{array}{l}\text { Dyskinesia or extrapyramidal symptoms (or } \\
\text { both) } \ddagger\end{array}$ & $1(0.1)$ & $3(0.4)$ & $6(0.8)$ & $6(0.8)$ & 0.020 & 0.062 \\
\hline Hot flushesł & $0(0.0)$ & $6(0.8)$ & $3(0.4)$ & $4(0.5)$ & 0.109 & 0.023 \\
\hline Cardiac or circulatory symptoms (or both) $\ddagger$ & $3(0.4)$ & $6(0.8)$ & $4(0.5)$ & $2(0.3)$ & 0.682 & 0.458 \\
\hline Other & $26(3.3)$ & $16(2.0)$ & $24(3.1)$ & $14(1.8)$ & 0.977 & 0.977 \\
\hline \multicolumn{7}{|l|}{ All events } \\
\hline Classified as serious adverse events $\ddagger$ & $3(0.4)$ & $2(0.3)$ & $3(0.4)$ & $0(0.0)$ & 0.882 & 0.676 \\
\hline
\end{tabular}

*One sided trend test (Kendall's $\sigma)$; null hypothesis: the event rate does not increase with the dose of metoclopramide.

†ne sided test (Fisher's exact) for the effect of any dose of metoclopramide; null hypothesis: the event rate in the pooled metoclopramide groups is no higher than in the control group. fExact $P$ values for the trend test were computed when the total number of events was $<20$. 


\begin{tabular}{|c|c|c|c|}
\hline Variable & $\begin{array}{c}\text { Nausea and vomiting 0-12 hours after } \\
\text { surgery }\end{array}$ & $\begin{array}{c}\text { Nausea and vomiting }>12-24 \text { hours after } \\
\text { surgery } \dagger\end{array}$ & Adverse drug reaction \\
\hline Female sex & $2.27(1.69 \text { to } 3.04)^{\star \star \star}$ & $2.38(1.59 \text { to } 3.56)^{\star \star \star \star}$ & 1.14 (0.89 to 1.45$) \S$ \\
\hline Age $>50$ years & $0.57(0.44 \text { to } 0.74)^{\star \star * *}$ & $1.93(1.24 \text { to } 2.99)^{* \star}$ & $1.93(1.49 \text { to } 2.50)^{\star * *}$ \\
\hline Obesity (body mass index $>30$ ) & 1.07 (0.84 to 1.36$) \S$ & 0.86 (0.63 to 1.17$) \S$ & $0.70(0.54 \text { to } 0.89)^{\star \star *}$ \\
\hline $\begin{array}{l}\text { History of postoperative nausea and vomiting or } \\
\text { motion sickness (or both) }\end{array}$ & $1.95(1.55 \text { to } 2.44)^{\star * \star}$ & $1.55(1.14 \text { to } 2.10)^{\star \star}$ & 0.96 (0.75 to 1.23$) \S$ \\
\hline Non-smoker & $2.18(1.57 \text { to } 3.04)^{\star * *}$ & $1.64(0.92$ to 2.94$) \S$ & 1.23 (0.90 to 1.68$) \S$ \\
\hline \multicolumn{4}{|l|}{ Dose of metoclopramide (versus none) } \\
\hline $10 \mathrm{mg}$ & 0.79 (0.59 to 1.05$)$ & 0.85 (0.57 to 1.27$)$ & 1.29 (0.92 to 1.81$)$ \\
\hline $25 \mathrm{mg}$ & $0.53(0.39 \text { to } 0.72)^{\star \star * *}$ & 1.02 (0.69 to 1.51$)$ & $1.55(1.11 \text { to } 2.15)^{\star \star}$ \\
\hline $50 \mathrm{mg}$ & $0.53(0.39 \text { to } 0.72)^{\star \star \star}$ & $0.55(0.36 \text { to } 0.86)^{\star \star}$ & $2.34(1.71 \text { to } 3.21)^{\star \star *}$ \\
\hline \multicolumn{4}{|l|}{ Type of surgery (versus average) } \\
\hline Hysterectomy & $1.77(1.28 \text { to } 2.45)^{\star \star \star *}$ & $1.72(1.05 \text { to } 2.82)^{*}$ & $1.46(1.06 \text { to } 2.03)^{*}$ \\
\hline Cholecystectomy & $1.45(1.03 \text { to } 2.04)^{*}$ & $1.86(1.07 \text { to } 3.22)^{*}$ & $1.05(0.73$ to 1.50$)$ \\
\hline Herniotomy & 0.89 (0.55 to 1.44$)$ & 0.53 (0.18 to 1.53$)$ & 0.99 (0.70 to 1.40$)$ \\
\hline Otolaryngological surgery & $1.38(1.03 \text { to } 1.87)^{*}$ & $0.18(0.05 \text { to } 0.65)^{\star \star}$ & 0.76 (0.56 to 1.04$)$ \\
\hline Thyroidectomy & $2.00(1.49 \text { to } 2.69)^{\star \star \star}$ & $1.72(1.02 \text { to } 2.89)^{*}$ & 0.87 (0.62 to 1.23$)$ \\
\hline Endoprothesis (intubation) & 0.85 (0.57 to 1.28$)$ & $2.31(1.42 \text { to } 3.76)^{\star \star \star}$ & $2.68(2.03 \text { to } 3.55)^{\star \star \star}$ \\
\hline Arthroscopy (intubation) & 1.28 (0.97 to 1.67$)$ & 0.65 (0.37 to 1.17$)$ & 0.99 (0.77 to 1.27$)$ \\
\hline Endoprothesis (regional) & 0.86 (0.64 to 1.17$)$ & $2.70(1.76 \text { to } 4.14)^{\star \star *}$ & $0.60(0.46 \text { to } 0.80)^{\star * *}$ \\
\hline Arthroscopy (regional) & $0.17(0.08 \text { to } 0.38)^{\star \star \star *}$ & $0.45(0.16$ to 1.29$)$ & $0.62(0.40 \text { to } 0.96)^{*}$ \\
\hline \multicolumn{4}{|l|}{ Alcohol consumption (versus none) } \\
\hline 1 to 14 drinks each week & $0.76(0.60 \text { to } 0.96)^{*}$ & $0.93(0.68$ to 1.29$) \S$ & 0.83 (0.66 to 1.05$) \S$ \\
\hline$>14$ drinks each week & $0.30(0.13 \text { to } 0.71)^{\star \star *}$ & $0.83(0.31$ to 2.22$) \S$ & 1.34 (0.88 to 2.03$) \ddagger$ \\
\hline \multicolumn{4}{|l|}{ Opioids (versus none) } \\
\hline $0-12$ hours after surgery & $1.31(1.02 \text { to } 1.69)^{*}$ & 1.37 (0.94 to 2.00$) \S$ & - \\
\hline$>12-24$ hours after surgery & - & $3.05(2.01 \text { to } 4.65)^{\star \star \star}$ & - \\
\hline \multicolumn{4}{|l|}{ Postoperative nausea and vomiting } \\
\hline $0-12$ hours after surgery & - & $3.34(2.09 \text { to } 5.36)^{\star * *}$ & - \\
\hline Rescue drugs needed 0-12 hour after surgery & - & $0.41(0.22 \text { to } 0.76)^{\star \star}$ & - \\
\hline
\end{tabular}

Rescue drugs needed 0-12 hour after surgery $\quad-\quad 0.41(0.22 \text { to } 0.76)^{\star *}$

${ }^{*} \mathrm{P} \leq 0.05 ;{ }^{* *} \mathrm{P}<0.01 ;{ }^{* *}{ }^{*} \mathrm{P}<0.001$.

tIncluding repeat episodes of postoperative nausea and vomiting.

fHypotension or tachycardia after receiving metoclopramide.

§Variable not in the model $(P>0.05)$. Odds ratios in the model were not adjusted for this variable.

ๆOne drink=0.25 litre beer, 0.1 litre wine, or $20 \mathrm{ml}$ spirits.

\section{Predictors of nausea and vomiting and adverse reactions}

Table 4 lists the results of multiple regression for predictors of early and late postoperative nausea and vomiting and adverse reactions (hypotension or tachycardia after the study drug was given). Only the $25 \mathrm{mg}$ and $50 \mathrm{mg}$ doses significantly reduced nausea and vomiting. The frequency of adverse reactions increased with the dose of metoclopramide (fig 3).

Known predictors of postoperative nausea and vomitingfemale sex, history of nausea and vomiting after surgery or motion sickness, non-smoking, and postoperative opioids-were associated with increased rates of postoperative nausea and vomiting. Late application of opioids increased postoperative nausea and vomiting much more than early application.

The frequency of nausea and vomiting and adverse reactions depended on the type of surgery. The pattern of this association was different for early and late events.

Like smoking, alcohol consumption was associated with less frequent postoperative nausea and vomiting. Whereas the number of cigarettes smoked each day had no effect, we detected a significant difference between moderate and higher alcohol consumption.

Early postoperative nausea and vomiting was less frequent in patients aged 50 or more but late episodes were more frequent, as were adverse reactions. Obesity was not associated with nausea and vomiting, but it seemed to protect against adverse reactions.

Late postoperative nausea and vomiting was more likely to occur in patients who had had nausea and vomiting in the early phase. Rescue drugs given for early postoperative nausea and vomiting prevented new events in the later time period.

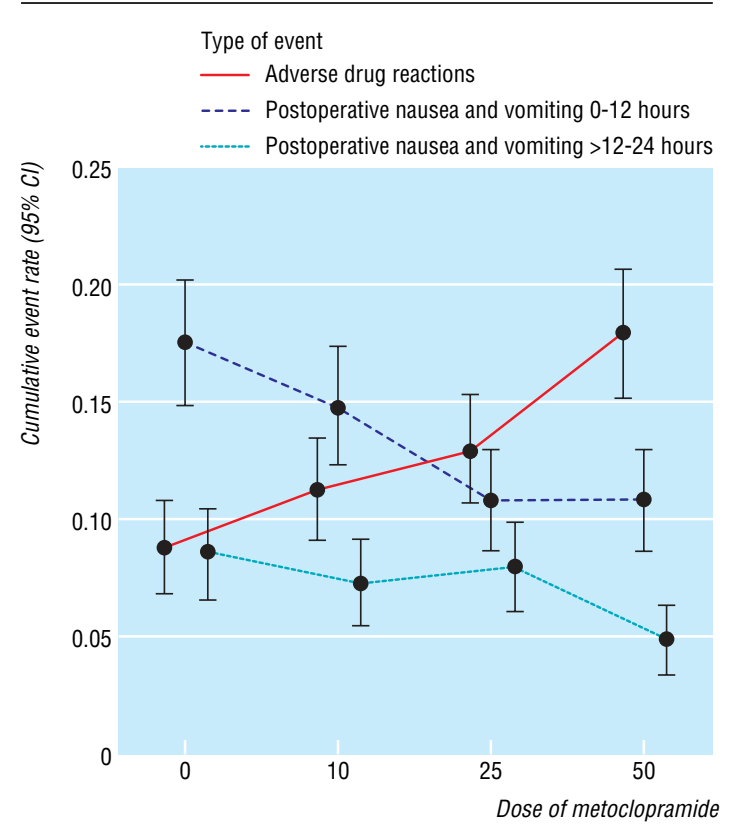

Fig 3 Rates of early and late postoperative nausea and vomiting and intraoperative adverse drug reactions (hypotension and tachycardia) in four treatment groups 


\section{Discussion}

No single antiemetic drug has proved to be a universal solution to postoperative nausea and vomiting. It is not feasible to give very high doses of such drugs because of saturation effects and safety, so combinations of antiemetic drugs are a possibility. We found that $25 \mathrm{mg}$ or $50 \mathrm{mg}$ metoclopramide added to the basic intervention of $8 \mathrm{mg}$ dexamethasone is effective, safe, and cheap.

\section{Strengths and limitations}

We investigated the dose-response relation between metoclopramide and postoperative nausea and vomiting. Although we had insufficient power to obtain precise information on rare events, we carried out a large prospective assessment of metoclopramide related adverse reactions. Thus, we can derive recommendations from our data, by weighing efficacy against safety. Because of the size of our study, our data on extrapyramidal symptoms are probably more reliable than those from a meta-analysis of 537 patients from 13 trials. ${ }^{511}$

Our study design allowed us to investigate only the effect of adding metoclopramide to dexamethasone, not the separate effects of each drug. Furthermore, the numbers needed to treat reflect the effectiveness of metoclopramide only as a secondary, not primary, intervention.

In retrospect, we should have recorded more details on hypotension and tachycardia. Although these adverse events were short lasting and self limiting in most cases, some facts beyond the clinical impression might have been useful (such as the need for treatment).

Metoclopramide was given to anaesthetised patients only. We have no information on discomfort felt after the drug was given to patients who were awake.

\section{Comparison with other studies}

A meta-analysis reported that $10 \mathrm{mg}$ metoclopramide was clinically ineffective and did not improve when combined with $8 \mathrm{mg}$ dexamethasone. ${ }^{5}$ Larger dosages, however, were as effective as ondansetron or droperidol when added to dexamethasone (odds ratios around 0.5). ${ }^{1}$

A randomised double blind trial with 240 children and adults per treatment arm found that $50 \mathrm{mg}$ metoclopramide was not effective for postoperative vomiting (odds ratio $0.83,0.45$ to 1.52 ) but significantly reduced postoperative nausea and vomiting (odds ratio $0.47,0.27$ to 0.84 ). ${ }^{12}$ Unfortunately, this paper did not say when the drug was given, and the trial was powered only for large effects. That study reported a higher rate of restlessness and extrapyramidal symptoms $(6 \%)$ than was seen in our study, perhaps because they studied children and adults and had a less precise differentiation between types of adverse events.

Other studies also found that $20 \mathrm{mg}$ metoclopramide was ineffective, possibly because of the small sample sizes (40, 129, and 51 patients per group). ${ }^{13-15}$ Furthermore, the timing of antiemetic prophylaxis seems to influence efficacy. ${ }^{17}$ In most of the studies, metoclopramide was given immediately after induction of anaesthesia, irrespective of its time of maximum effect and short half life.

Despite the neuroleptic properties of metoclopramide, its addition to dexamethasone did not increase rates of headache, dizziness, sedation, or dry mouth. The incidences seen in our trial are similar to those of low dose droperidol. ${ }^{2}$

\section{Clinical implications and future research}

Although the addition of $10 \mathrm{mg}$ metoclopramide to dexamethasone is a standard prophylaxis for postoperative nausea and vomiting in Germany, ${ }^{18}{ }^{19}$ we think that this dosage is suboptimal.
We recommend a combination of $8 \mathrm{mg}$ dexamethasone and 50 mg metoclopramide, given 30-60 minutes before the end of surgery. If house policy allows postoperative antiemetic prophylaxis, $8 \mathrm{mg}$ dexamethasone and $25 \mathrm{mg}$ metoclopramide should be given intraoperatively. Additional drugs can then be given after surgery, but the patient's risk profile should be taken into account. Rescue drugs should be given after postoperative nausea and vomiting to prevent repeat episodes.

Although adverse reactions such as extrapyramidal symptoms are rare, clinicians should be aware of them and should be familiar with suitable treatment options.

To improve existing risk scores used in guidelines, the role of different types of surgery and of alcohol consumption should be investigated further. ${ }^{20}$ Timing of administration should also be investigated, and a suitable dose of metoclopramide should be compared with a 5-hydroxytryptamine receptor antagonist (both combined with dexamethasone).

Thanks to Merck KgaA, Darmstadt, and ratiopharm GmbH, Ulm, Germany, for providing the study drugs and for financial support.

Contributors (other than authors): B Aedtner, K Auerswald, S Berg, TS Elias, TM Goerlich, K Gräfe, F Graf, K Gunia, B Hänsel, R Hennebach, G Hertel-Gilch, T Hirschberg, T Jäger, H Krowiasch, C Kruse, J Krutzsch, A Kuhn, I Kühnert, S Maidatschewski, H Merxbauer, D Paffrath, M Parschauer, F Pfeifer, U-C Pietsch, C Rudolph, L Schaffranietz, M Schlender, S Schmidt, H Schmidt-Runke, K Schönfelder, D Schotte, K Sipli, S Stengel, R Tarrasch, V Thieme, and J Wagner (Department of Anaesthesiology and Intensive Care Medicine, University of Leipzig); J Gernhardt, J Al-Kuhay, U Schmidt, A Schuldt, A Teube, and C Waselan (Bad Düben Forest Hospital); M Mühl, H Petzold, R Reißmann, B Richter, S Wagler, and K Wallenborn (Wurzen District Hospital); D Lawonn, U Rosenkranz, K Weise, and T Zirk (Grimma District Hospital); S Blache, T Kleue, M Rudolph, M Schedewi, and C Walter (Weissenfels). JW, GG, and DO designed the trial and drafted the study protocol, case report forms, and study guidelines; the other authors revised the study protocol critically. JW, DB, KB, HW, AR, UK, TK, and MW were mainly responsible for conducting the study in the eight centres. GG was head of data management and performed the statistical analyses. JW and GG drafted the manuscript; the other authors revised the manuscript critically. All contributors who were not authors discussed the study guidelines and case report form and helped conduct the study and collect data. DO is guarantor.

Funding: Merck KgaA, Darmstadt, Germany and ratiopharm GmbH, Ulm, Germany, provided the study drugs and partial financial support. These companies did not influence the study protocol or its conduct, or the evaluation of the study data.

Competing interests: None declared.

Ethical approval: Ethics committee of the Medical Faculty of the University of Leipzig and the medical associations of the German states of Saxony and Saxony-Anhalt.

1 Apfel CC, Korttila K, Abdalla M, Kerger H, Turan A, Vedder I, et al. A factorial trial of six interventions for the prevention of postoperative nausea and vomiting. N Engl J Med 2004;350:2441-51

\section{What is already known about this topic}

The results of trials on the use of metoclopramide to prevent postoperative nausea and vomiting have been contradictory

\section{What this study adds}

This large randomised trial showed that the addition of 25 $\mathrm{mg}$ or $50 \mathrm{mg}$ metoclopramide to dexamethasone (given intraoperatively) reduces postoperative nausea and vomiting

The optimal dose will depend on the hospital's policy on prophylaxis for postoperative nausea and vomiting 


\section{Research}

2 Fortney JT, Gan TJ, Graczyk S, Wetchler B, Melson T, Khalil S, et al. A comparison of the efficacy, safety, and patient satisfaction of ondansetron versus droperidol as antiemetic for elective outpatient surgical procedures. Anesth Analg 1998;86:731-8

3 Koivuranta M, Läärä E, Snåre L, Alahuhta S. A survey of postoperative nausea and vomiting. Anaesthesia 1997;52:443-9.

4 Wang JJ, Ho ST, Lee SC, Liu YC, Liu YH, Liao YC. The prophylactic effect of dexamethasone on postoperative nausea and vomiting in women undergoing thyroidectomy: a comparison of droperidol with saline. Anesth Analg 1999;89:200-3.

5 Henzi I, Walder B, Tramer MR. Metoclopramide in the prevention of postoperative nausea and vomiting: a quantitative systematic review of randomized, placebocontrolled studies. Br J Anaesth 1999;83:761-71.

6 Olthoff D. Antiemetika. In: Olthoff D, ed. Arzneimittelanwendungen in der Anästhesie. Stuttgart: Wissenschaftliche Verlagsgesellschaft, 2003:511-34.

7 Fujii Y, Tanaka H, Toyooka H. The effects of dexamethasone on antiemetics in female patients undergoing gynecologic surgery. Anesth Analg 1997;85:913-7.

8 Maddali MM, Mathew J, Fahr J, Zarroug AW. Postoperative nausea and vomiting in diagnostic gynaecological laparoscopic procedures: comparison of the efficacy of the combination of dexamethasone and metoclopramide with that of dexamethasone and ondansetron. J Postgrad Med 2003;49:302-6.

9 Tzeng JI, Hsing CH, Chu CC, Chen YH, Wang IJ. Low-dose dexamethasone reduce nausea and vomiting after epidural morphine: a comparison of metoclopramide with saline. J Clin Anesth 2002:14:19-23.

10 Nesek-Adam V, Grizelj-Stojèiæ E, Mršiæ V, Smiljaniæ A, Rasiæ Z, Èala Z. Prophylactic antiemetics for laparoscopic cholecystectomy: droperidol, metoclopramide, and droperidol plus metoclopramide. J Laparoendosc Adv Surg Tech A 2004;14:212-8.

11 Flather MD, Farkouh ME, Pogue JM, Yusuf S. Strengths and limitations of meta-analysis: larger studies may be more reliable. Control Clin Trials 1997;18:568-79.

12 Apfel CC, Kranke P, Katz MH, Goepfert C, Papenfuss T, Rauch S, et al. Volatile anaesthetics may be the main cause of early but not delayed vomiting: a randomized controlled trial of factorial design. Br J Anaesth 2002;88:659-68.

13 Eberhart LHJ, Seeling W, Ulrich B, Morin AM, Georgieff M. Dimenhydrinate and metoclopramide alone or in combination for prophylaxis of PONV. Can J Anesth 2000;47:780-5.

14 Piper SN, Suttner SW, Röhm KD, Maleck WH, Larbig E, Boldt J. Dolasetron, but not metoclopramide prevents nausea and vomiting in patients undergoing laparoscopic cholecystectomy. Can J Anesth 2002;49:1021-8.

15 Quaynor H, Ræder JC. Incidence and severity of postoperative nausea and vomiting Quaynor $\mathrm{H}$, Ræder JC. Incidence and severity of postoperative nausea and vomiting
are similar after metoclopramide $20 \mathrm{mg}$ and ondansetron $8 \mathrm{mg}$ given by the end of

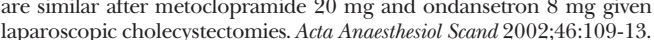

16 Korttila KT, Jokinen JD. Timing of administration of dolasetron affects dose necessary to prevent postoperative nausea and vomiting.J Clin Anesth 2004;16:364-70.
17 Wang JJ, Ho ST, Tzeng JI, Tang CS. The effect of timing of dexamethasone administration on its efficacy as a prophylactic antiemetic for postoperative nausea and vomiting. Anesth Analg 2000;91:136-9.

18 Eberhart LHJ, Morin AM, Felbinger TW, Falkner Y, Georgieff M, Seeling W. Results of a survey concerning postoperative nausea and vomiting [in German]. Anasthesiol Intensizmed Notfallmed Schmerzther 1998;33:545-51.

19 Schöneck R, Speck-Hergenröder J, Eberhart LHJ. Anaesthetic procedures and use of antiemetics in ambulatory anaesthesia [in German]. Anaesthes Intensivmed 2002;43:695-9.

20 Gan TJ, Meyer T, Apfel CC, Chung F, Davis PJ, Eubanks S, et al. Consensus guidelines for managing postoperative nausea and vomiting. Anesth Analg 2003;97:62-71.

(Accepted 31 May 2006)

doi $10.1136 /$ bmj. 38903.419549 .80

Department of Anaesthesiology and Intensive Care Medicine, University of Leipzig, D-04103 Leipzig, Germany

Jan Wallenborn anaesthesiologist

Katrin Behrends anaesthesiologist

Andrea Rohrbach anaesthesiologist

Martin Wiegel anaesthesiologist

Derk Olthoff professor

Coordination Centre for Clinical Trials Leipzig, University of Leipzig, D-04107 Leipzig

Götz Gelbrich senior biometrician

Bad Düben Forest Hospital, D-04849 Bad Düben, Germany

Detlef Bulst head of department of anaesthesiology

Wurzen District Hospital, D-04808 Wurzen, Germany

Hasso Wallenborn head of department of anaesthesiology

Grimma District Hospital, D-04668 Grimma, Germany

Uwe Krause head of department of anaesthesiology

Weissenfels District Hospital, D-06667 Weissenfels, Germany

Thomas Kühnast head of department of anaesthesiology

Correspondence to: G Gelbrich goetz.gelbrich@kksl.uni-leipzig.de 